\title{
Outcomes after Transhiatal Esophagectomies in an Eastern-European Low-Volume Center
}

\author{
Radu Neagoe ${ }^{1}$, Septimu Voidazan ${ }^{2}$, Mihaly Szocs $^{3}$, Daniela Tatiana Sala ${ }^{1}$, Serban Bancu ${ }^{1}$, Gheorghe Mulhfay ${ }^{3}$ \\ ${ }^{1}$ Second Department of General Surgery, Emergency Mureş County Hospital, University of Medicine and Pharmacy, Târgu Mureş, Romania \\ ${ }^{2}$ Department of Epidemiology, University of Medicine and Pharmacy, Târgu Mureş, Romania \\ ${ }^{3}$ Department of ENT Surgery, Emergency Mureș County Hospital, University of Medicine and Pharmacy, Târgu Mureş, Romania
}

Background: The present study proposes to analyze the results obtained after transhiatal esophagectomies (THE), from the perspective of an Eastern European surgical center with low esophageal resection volume (LV).

Aims: Our analysis, which to the authors' knowledge is the first of its kind in Romania, has the purpose of comparing our results with those obtained in higher or similar volume centers, in order to derive conclusions regarding the quality of therapeutic management for patients diagnosed with esophageal cancer in Romania. Study Design: Retrospective observational study.

Methods: In total, 70 patients were included, in whom THE was performed during the period 1997-2013 by six senior surgeons. The majority of our patients had esophageal cancers $(n=66 ; 94.3 \%)$; we also performed 4 THE procedures for benign conditions $(n=3 ; 4.27 \%)$ and esophageal perforation $(\mathrm{n}=1 ; 1.42 \%)$.

Results: The majority of cancer-group patients had T3/ $\mathrm{N}+$ tumors. The nodal involvement in the T2, T3 and T4 categories was $9.9 \%, 21.6 \%$ and $35.1 \%$, respectively.
Complications were identified in 45 patients $(68.2 \%)$, with the majority being represented by pulmonary complications (16 patients; $24.3 \%$ ) and cervical leaks (15 cases; 22.7\%). In-hospital mortality was 9.09\%. We found a one-year overall survival rate of $58.7 \%$ (95\%CI: $51.7-65.7 \%$ ), $27.2 \%$ at 2 years (95\%CI: $21.2-$ $36.2 \%)$ and $10.5 \%$ at 3 years (95\%CI: $6.5-14.5 \%)$. The median survival rate was estimated to be 16 months.

Conclusion: Morbidity and in-hospital mortality after THE was performed in low-volume centers, despite being significantly higher than reported in HV centers, could be kept at reasonable rates. In our opinion, the measures which have the potential to raise the standard of care for patients diagnosed with esophageal cancer in Romania are represented by the standardization of therapeutic and diagnostic protocols for esophageal cancer and the centralization of these major oncologic interventions in surgical excellence centers.

Keywords: Low-volume center, morbidity, survival transhiatal esophagectomy
Surgery alone or associated with radio-chemo-therapy (RCT) as a multimodal approach remains the main method of treatment for resectable esophageal cancer $(1,2)$. Right transthoracic esophagectomy (Ivor Lewis technique) and transhiatal esophagectomy (Orringer procedure) are the most widely used standard techniques; the superiority of either of these methods is still a subject of intense controversy $(2,3)$. There is increasing evidence that among factors which influence the postoperative results, including long-term survival, in patients who undergo complex oncological resections such as esophagectomy, the hospital-volume and surgeon-volume play an important role (4-6). 
In a recently published retrospective study (3), we comparatively analyzed the outcomes of transthoracic and transhiatal esophagectomies performed in our department in a period of 15 years. Starting from the same database, which was then updated and actualized, the present study proposes to analyze the results obtained after transhiatal esophagectomies (THE), from the perspective of an Eastern European surgical center with low esophageal resection volume (LV). Our analysis, which to the best of our knowledge is the first of its kind in Romania, has the purpose of comparing our results with those obtained in higher or similar volume centers, in order to derive conclusions regarding the quality of therapeutic management for patients diagnosed with esophageal cancer in Romania.

\section{MATERIALS AND METHODS}

This is a retrospective study analyzing the results of transhiatal esophagectomies (THE) performed during 1997-2013 in the $2^{\text {nd }}$ Surgical Department, Emergency Mures County Hospital, Romania. We started from a database which initially included all reconstructions performed for benign or malignant esophageal diseases; in the period mentioned, we performed 203 esophageal reconstructions.

The data were retrospectively collected until 2010, through the analyses of clinical observation sheets and operatory and anatomopathological protocols. After 2010, the data collection was done prospectively.

As previously stated, the present study focused only on THE indicated as a surgical treatment for esophageal cancer or other benign diseases during the mentioned time frame, analyzing the results from the perspective of the center's surgical volume. Therefore, we excluded patients in whom the approach was different from that studied (73 transthoracic right or left, toracophrenolaparotomy), patients in whom esophagectomy, most often carried out in an emergency, was not followed by a reconstruction of the esophagus ( 5 cases of acute caustic ingestion, which resulted in the patient's death in most cases), and patients with bypass procedures for caustic strictures or non-resectable esophageal cancer (55 cases). We did not include patients with upper third tumors for whom curative chemotherapy (CT) was deemed appropriate in our database. The majority of these cases were initially diagnosed in gastroenterology or ENT surgery departments, being referred directly toward oncologic treatment. All surgeries were performed by 6 senior surgeons with comparable individual surgeon volume and prior level of training.

The standard preoperative workup for esophageal cancer included clinical examination, radiologic and endoscopic evaluation and imagistics. Despite offering suggestive images for non-resectability in some cases, contrast radiography was gradually replaced by endoscopy, which provides a direct image, allowing for biopsy and histopathological examination. The tumor extension and stage were assessed by computer tomography; we did not benefit from the use of endoscopic ultrasonography or positron emission tomography (PET). In the last period of our study, patients with locally advanced disease (defined as either T3 or N1) were assigned to neoadjuvant RCT; unfortunately, most of them either refused this initial treatment or the treatment response could not be properly evaluated, meaning that this variable was excluded from the analysis. For patients operated upon for non-oncological diseases, the preoperative examination protocol included clinical examination, contrast radiography and endoscopy, CT scan and manometry. All patients signed an informed written consent form, and the study was performed after the hospitals ethic committee approval.

\section{Surgical procedure}

In all cases, subtotal transhiatal esophagectomy was performed using the technique described by Orringer (7). The resectability was first confirmed through a median laparotomy, and then the inferior mediastinal esophagus was bluntly dissected under direct vision, through enlargement of the esophageal hiatus; this operatory step is greatly facilitated by practicing left cervicotomy and bipolar dissection of the esophagus. Abdominal compartment lymphadenectomy addresses the nodes along the common hepatic artery, left gastric artery, proximal splenic artery, and sometimes the celiac trunk; these vessels were practically bared down to the adventiceal level. The gastric tube was the preferred esophageal substitute, which was advanced in most cases ortotopically to the cervical level; we always used pilorotomy for gastric drainage. The cervical step consisted of an end-to-site single layer hand sewn esophagogastric anastomosis; we did not benefit from the contribution of mechanical sutures. A nasogastric tube was constantly used, manually guided to the pyloric region. The operations ended with the placement of an alimentation jejunostomy; opening of the pleural cavities, either accidental or intentional, achieved the pleural drainage.

The histopathological examinations were performed by dedicated gastro-intestinal pathologists, which were further standardized and reported.

\section{Patient follow-up}

Patients were observed in the intensive care unit (ICU) until extubation and normalization of vital functions. Enteral nutrition was started on postoperative day 2 , by administering fluids through the jejunostomy. Later, we gave up routine radiological control of the integrity of the cervical anastomosis. Postoperative course was noted, as were prolonged need for ventilatory support, number of days spent 
TABLE 1. Demographic and clinicopathological aspects in cancer-lot patients

\begin{tabular}{|c|c|c|c|}
\hline Variables & $\begin{array}{c}\text { Adeno- } \\
\text { carcinoma } \\
\text { No=12 }\end{array}$ & $\begin{array}{c}\text { Squamous cell } \\
\text { carcinoma } \\
\mathrm{No}=54\end{array}$ & $\begin{array}{c}\text { Total } \\
\text { No }=66\end{array}$ \\
\hline $\operatorname{Sex}(F / M), n(\%)$ & $\begin{array}{c}3(25.0) / 9 \\
(75.0)\end{array}$ & $\begin{array}{c}6(11.1) / 48 \\
(88.8)\end{array}$ & $\begin{array}{c}9(13.6) / 57 \\
(86.4)\end{array}$ \\
\hline Age, median (range) & $\begin{array}{c}60 \\
(42-71)\end{array}$ & $\begin{array}{c}58.5 \\
(41-80)\end{array}$ & $\begin{array}{c}59 \\
(41-80)\end{array}$ \\
\hline \multicolumn{4}{|l|}{ Reconstruction type, n (\%) } \\
\hline Left colon & $1(8.3)$ & $1(1.9)$ & $2(3.0)$ \\
\hline Right ileocolon & $1(8.3)$ & $2(3.6)$ & $3(4.5)$ \\
\hline Stomach orthotopic & $10(83.3)$ & $50(92.6)$ & $60(90.9)$ \\
\hline Stomach retrosternal & $0(0)$ & $1(1.9)$ & $1(1.5)$ \\
\hline \multicolumn{4}{|l|}{ Tumor level } \\
\hline Lower- third, n (\%) & $11(91.6)$ & $18(33.3)$ & $30(45.5)$ \\
\hline Mid-third, n (\%) & $1(8.4)$ & $30(55.6)$ & $30(45.5)$ \\
\hline Upper-third, n (\%) & $0(0)$ & $6(11.1)$ & $6(9.0)$ \\
\hline \multicolumn{4}{|l|}{ Tumor dimensions } \\
\hline Length, median (range) & $30(20-65)$ & $34.5(7-65)$ & $34(7-65)$ \\
\hline Depth, median (range) & $20(10-35)$ & $19(10-55)$ & $20(10-55)$ \\
\hline G1 n (\%) & $2(16.7)$ & $9(16.6)$ & $11(16.7)$ \\
\hline G2 n (\%) & $8(66.6)$ & $35(64.8)$ & $43(65.2)$ \\
\hline G3 n (\%) & $2(16.7)$ & $10(18.6)$ & $12(18.1)$ \\
\hline \multicolumn{4}{|l|}{ Hospital-stay (days) } \\
\hline median (range) & $17(7-31)$ & $16.5(4-31)$ & $17(4-31)$ \\
\hline \multicolumn{4}{|l|}{ ICU-stay (days) } \\
\hline median (range) & $6(3-13)$ & $7(3-22)$ & $7(3-22)$ \\
\hline T1, no (\%) & $0(0.0)$ & $1(1.9)$ & $1(1.5)$ \\
\hline $\mathrm{T} 2$, no (\%) & $1(8.3)$ & $15(27.7)$ & $16(24.2)$ \\
\hline T3, no (\%) & $8(66.7)$ & $34(63.0)$ & $42(63.6)$ \\
\hline T4, no (\%) & $3(25.0)$ & $4(7.4)$ & $7(10.7)$ \\
\hline N0, no $(\%)$ & $3(25.0)$ & $15(27.7)$ & $18(27.3)$ \\
\hline N1, no $(\%)$ & $5(41.7)$ & $30(55.6)$ & $35(53.0)$ \\
\hline N2, no (\%) & $4(33.3)$ & $9(16.7)$ & $13(19.7)$ \\
\hline
\end{tabular}

in intensive care and in the hospital, postoperative complications and hospital mortality, with the latter being defined as all deaths occurring within 30 days postoperatively. After discharge, patients were followed-up every 3 to 6 months by the operating surgeon, with all observations being recorded prospectively. Patients included in the study were followed-up until they were lost to follow-up, the study ended or the patients died; the median follow-up was 1.28 years (470 days), with a range between 12 days and 3.07 years.

\section{Statistical analysis}

Statistical analysis was performed using the MedCalc Software (bvba Version 12.3.0, Mariakerke, Belgium).
TABLE 2. Lymph nodes status according to pT-category

\begin{tabular}{cccccc}
\hline & N0 & N1 & N2 & Removed nodes & Involved nodes (\%) \\
\hline T1 & 0 & 0 & 0 & 8 & 0.0 \\
T2 & 0 & 12 & 0 & 121 & 9.9 \\
T3 & 0 & 57 & 24 & 375 & 21.6 \\
T4 & 0 & 3 & 31 & 97 & 35.1
\end{tabular}

Categorized variables were expressed through $\mathrm{nr} \%$. The survival analysis was performed using the Kaplan Meier method, with the log-rank test being utilized for univariate comparisons.

\section{RESULTS}

The study population included 70 patients with THE performed for heterogeneous diseases etiology, the majority being represented by esophageal cancers $(\mathrm{n}=66 ; 94.3 \%)$, most often squamous cell carcinoma (SCC), and less frequently, adenocarcinomas (AKE). We also performed THE for benign conditions $(n=4)$ : two cases of caustic strictures $(2.85 \%)$, a case of achalasia (1.42\%) and an esophageal perforation (1.42\%). Mean age of the entire study group was 59.5 years, with a median of 59 years (range: 41-80 years). Reconstruction was possible during the same time with resection in 69 cases; in the case of esophageal perforation, this was performed 6 weeks after esophagectomy. The stomach was the preferred esophageal substitute ( $\mathrm{n}=61)$; in the majority of cases, it was used as a gastric tube $(\mathrm{n}=54,88.5 \%)$, but rarely the whole stomach $(\mathrm{n}=7,11.47 \%)$. Most often, it was ascended ortotopically to the cervical level $(\mathrm{n}=60-\%)$; in one case, the retrosternal route was preferred due to mediastinal effraction of the tumoral esophagus. Colon interpositions were performed in 9 patients $(12.85 \%)$; ileo-colo-esophagoplasties were carried out in 4 cases of esophageal cancer and 4 benign diseases; in one case a left colon esophagoplasty was deemed necessary.

We performed 2 THE in young patients with caustic strictures of the esophagus, followed by retrosternal ileocolonic interpositions. THE was also performed in a case of refractory achalasia, after two unsuccessful myotomies. Our study included a THE performed as an emergency procedure, for an iatrogenic midesophageal perforation; in this case, the reconstruction was performed 6 months afterwards with ileocolonic interposition and internal mammary supercharge on ileocolic vessels.

Etiologically, esophageal cancer was by far the main indication for THE; therefore, in the following, we will analyze this category of patients. The cancer-lot included 66 patients, histologically mostly represented by SCC $(\mathrm{n}=54,81.82 \%)$, and less by AKE $(n=12,18.18 \%)$. The demographics and clinicopathological aspects of cancer patients are represented in Table 1.

The vast majority of patients had $\mathrm{T} 3 / \mathrm{N}+$ tumors, with the tumor confined to the organ but presenting lymphadenopathy. 
TABLE 3. Postoperative complications after THE for malignant disease - surgical complications in accordance with Clavien Dindo classification

\begin{tabular}{|c|c|c|c|c|}
\hline Complications & & $\begin{array}{c}\text { Adenocarcinoma } \\
\quad \mathrm{No}=12\end{array}$ & $\begin{array}{l}\text { Squamous cell carcinoma } \\
\qquad \mathrm{No}^{2}=54\end{array}$ & $\begin{array}{c}\text { Total } \\
\text { No }=66\end{array}$ \\
\hline Without complications & & $7(58.3)$ & $22(40.7)$ & $29(43.9)$ \\
\hline Cardiac & & $1(8.3)$ & $4(7.2)(2)^{*}$ & $5(7.5)$ \\
\hline Pulmonary & & $4(33.3)$ & $12(22.2)$ & $16(24.3)$ \\
\hline Pulmonary embolism & & $0(0.0)$ & $1(1.8)(1)^{*}$ & $1(1.5)$ \\
\hline Grade I & Wound infection & $0(0.0)$ & $2(3.6)$ & $2(3.0)$ \\
\hline \multirow[t]{3}{*}{ Grade III } & Bowel obstruction & $0(0.0)$ & $1(1.8)$ & $1(1.5)$ \\
\hline & Hemorrhage & $0(0.0)$ & $2(3.6)$ & $2(3.0)$ \\
\hline & Leaks & $1(8.3)$ & $13(24.1)$ & $14(21.2)$ \\
\hline Grade IV & Conduit necrosis & $0(0.0)$ & $1(1.8)$ & $1(1.5)$ \\
\hline \multirow[t]{2}{*}{ Grade V } & Leaks & $0(0.0)$ & $1(1.8),(1)^{*}$ & $1(1.5),(1)^{*}$ \\
\hline & Conduit necrosis & $0(0.0)$ & $2(3.6),(2)^{*}$ & $2(3.0),(2)^{*}$ \\
\hline Total & $6(50.0)$ & $39(72.2)$ & $45(68.2)$ & \\
\hline
\end{tabular}

()*-hospital mortality (30-day mortality)

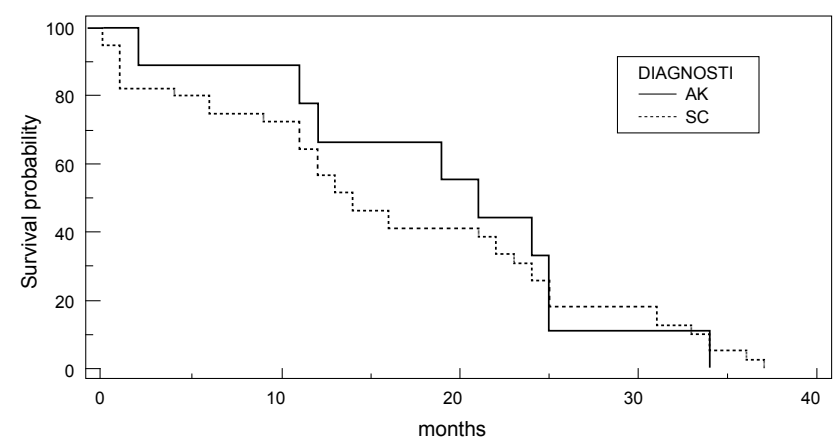

FIG. 1. Survival according to the histopathological type of tumor

With regard to the quality of lymph node dissection, the total number of removed lymph nodes was 601, of which 127 $(21.1 \%)$ were metastatically affected. The median number of retrieved nodes per patient was 9 (range: 4-19). According to T-categories, we did not find nodal involvement in pT1-category patients, but nodal involvement was as high as $35.1 \%$ in T4-category patients. In T2 stage, nodal involvement was identified in $9.9 \%$, and in $\mathrm{T} 3$ stage nodal involvement was in $21.6 \%$ (Table 2).

Complications were identified in 45 (68.2\%) patients, with postoperative morbidity being detailed in Table 3 , in accordance with Clavien Dindo classification of surgical complications.

We found respiratory complications in 16 patients $(24.3 \%)$ : 13 cases of pleuresis and 3 cases of postoperative pneumonia. Cervical anastomotic leaks were found in 15 cases $(22.7 \%)$, the majority of them being treated conservatively; one case was complicated by a severe mediastinitis, septic shock and inhospital death. We encountered 3 cases of graft necrosis, two of which ended with severe mediastinitis, septic shock and post-

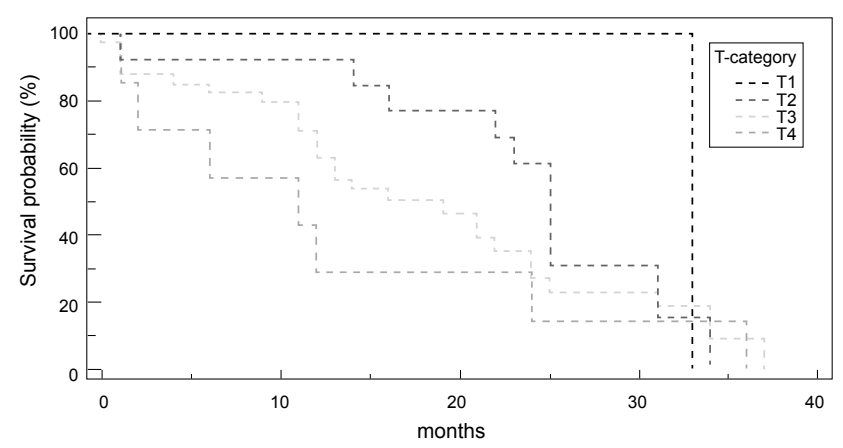

FIG. 2. Survival according to pT-category

operative death. In-hospital mortality was $9.09 \%$; the causes of death were non-surgical (1 embolism, and 2 cardiac arrests) or surgical (1 complicated fistula, and 2 transplant necrosis).

With regard to late complications, we noted 8 patients $(11.9 \%)$ with benign strictures of cervical anastomosis, 7 operated upon for cancer and 1 patient operated on for iatrogenic perforation of the esophagus, in whom $5(62.5 \%)$ had a cervical fistula that was treated conservatively. In 6 cases, stricture resolved after endoscopic dilation, while in 2 situations this was achieved with re-intervention by practicing enlargement of the cervical eso-gastric anastomosis. Recurrence was encountered in 32 cases, all representing the cause of death.

\section{Survival}

In the following-up period, we lost contact with 6 patients of our lot. As a consequence, the survival curves were calculated for 60 patients. The mortality rate for our patients over the study period was calculated to be $80.3 \%$ (49 deaths). We found a one-year overall survival rate of $58.7 \%$ (95\% CI: 51.7 $65.7 \%), 27.2 \%$ at 2 years ( $95 \%$ CI: $21.2-36.2 \%$ ) and $10.5 \%$ at 


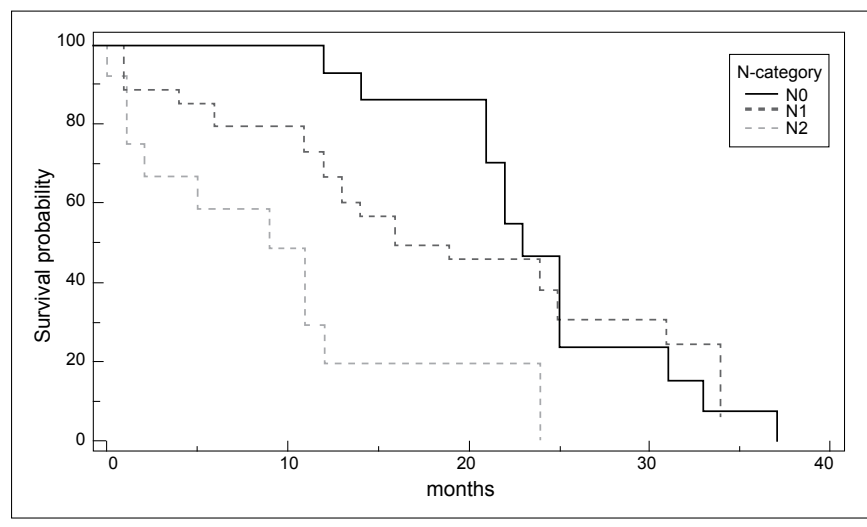

FIG. 3. Survival according to $\mathrm{pN}$-category

3 years (95\% CI: $6.5-14.5 \%)$. The median survival rate was estimated to be 16 months. Taking histopathological type of the tumor into consideration, in AKE we found a one-year survival rate of $66.7 \%$ (95\% CI: 51.0-82.4\%), a 2 year survival of $33.3 \%$ (95\% CI: $17.6-49.1 \%$ ) and a 3 -year survival of $11.1 \%$ (95\% CI: 5.45-15.2\%). In SCC, the one-year survival rate was $56.9 \%$ (95\% CI: $49.0-64.8 \%$ ), 2-year survival rate was $25.9 \%$ (95\% CI: $18.9-32.9 \%$ ) and the 3-year survival rate was $9.3 \%$ (95\% CI: 5.2-12.4\%) (Figure 1).

Depending on the pT-category, the 1-year survival rate ranged from $100 \%$ in pT1-category to $28.6 \%$ in T4-category patients. We could appreciate a survival rate for pT3-category patients of $27.2 \%$ and $6.4 \%$ at 2- and 3-years postoperatively, respectively (Figure 2 ).

Depending on nodal involvement, the 1-year survival ranged from $92.2 \%$ (95\% CI: $81.2-95.2 \%$ ) in N0 stage to $19.4 \%$ (95\% CI: $17.5-24.4 \%)$ in N2 stage. With 2- year survival, it varies from $43.1 \%$ (95\% CI: $29.9-56.3 \%$ ) in the N0 stage to $28.5 \%$ (95\% CI: $18.2-35.6 \%)$ in the N1 stage (stage N2 is no longer in discussion) (Figure 3).

Depending on the presence of postoperative complications, the 1-year survival was $53.9 \%$ (95\% CI $45.2-53.9 \%)$, the 2-year survival was $25.3 \%$ (95\% CI: $18.3-32.3 \%)$ and with a 3-year survival of $4.1 \%$ (95\% IC: $3.1-6.2 \%$ ). In patients with no postoperative complications, the 1-year survival was $68.7 \%$ (95\% CI: $57.1-80.3 \%$ ), the 2-year survival was $31.2 \%$ (95\% CI: 19.6-42.8\%) and the 3-year survival was 6.2\% (95\% CI: 4.8-11.8\%) (Figure 4).

\section{DISCUSSION}

We reviewed a series of THE performed in a low volume center with the aim of comparing our results to the outcomes in the literature.

Esophagectomy, whether for benign or malignant disease, is a major procedure that probably carries the highest morbid-

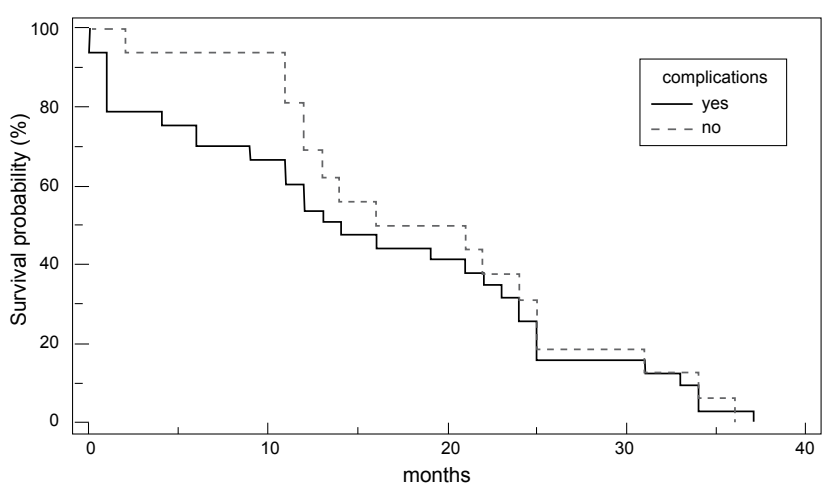

FIG. 4. Survival according to the postoperative complications

ity and operative mortality of any elective surgical procedures (8). The transhiatal approach has gained worldwide popularity in the last 35 years since Orringer "rediscovered" it in 1976 $(7,9,10)$; the rationale of this approach resides in the avoidance of thoracotomy, thus thereby reducing the risks of pulmonary complications and intrathoracic anastomotic leaks.

For more than ten years, the fact that postoperative morbidity and mortality after esophageal resection is linked to hospital-volume and surgeon experience has been established $(5,6,9,11,12)$. A high-volume (HV) center is defined by many authors $(9,11,12)$ as a hospital which performs more than 10-12 esophagectomies per year; this paper reports an experience with THE performed by a collective of 6 senior surgeons during a 17year period. With a total of 70 THE performed during the analyzed period, our experience is situated among low-volume (LV) centers (under 5 procedures/year), as described by Dimick et al. (12).

The study population included 70 patients with THE, performed for a heterogeneous group of diseases, the majority being represented by esophageal cancer. THE was chosen for statistical analysis for two principal reasons: firstly, these surgeries were performed in a relatively stable number on a yearly basis during the entire period of study, and secondly, as opposed to the transthoracic interventions, these surgeries were performed by a group of surgeons with a similar level of training. In the cancer group, the number of patients with AKE was significantly lower compared with the SCC-group, which is compatible with epidemiologic aspects of esophageal cancer in Romania $(3,13)$.

We also encountered few THE in individuals with benign esophageal diseases i.e. caustic strictures, achalasia and iatrogenic esophageal perforation. Esophagectomy for caustic strictures is still a matter of controversy; even if the risk of malignant transformation is real, the process will develop over a 25-30 year period $(14,15)$. On the contrary, the risks of esophageal stripping in the presence of esophagitis and periesophagitis are well known, with consequent pleural effractions and pulmonary complications (16). In our group, we had 2 young patients with esophageal caustic strictures for whom 
esophagectomy was deemed to be indicated due to long life expectancy.

Our statistics included a case of THE for a complicated achalasia; the indication of esophageal resection in achalasia is exceptional (less than 5\% of cases) and encompasses repeated failures of endoscopic or surgical approaches, with persistent dysphagia and related evolutionary complications such as mega-esophagus $(17,18)$.

We also performed THE in a case of iatrogenic perforation of the mid-esophagus during endoscopy, which was previously published (19); in fact, this is the only situation where we initially performed an emergency esophagectomy followed by a colonic interposition with internal mammary supercharge on ileocolic vessels 6 weeks later. The "supercharged" ileocoloplasty is considered to be a last but viable solution in cases in which the risk of substitute ischemia is high (20).

The main indication for THE remains esophageal cancer. Opponents of the transhiatal approach argue that neglecting the general principles of oncologic surgery i.e. good exposure via a thoracotomy, dissection at a distance from the tumor, and especially disrespecting the mediastinal lymphadenectomy, limit the ability of achieving an $\mathrm{R} 0$ resection, resulting in higher rates of locoregional recurrence and worse overall survival $(3,21)$.

The majority of our cancer-group patients had locally advanced disease; furthermore, preoperative RCT could not be assessed due to previously mentioned reasons. In this perspective, the choice of transhiatal approach could be difficult to explain. There were of course objective reasons, such as the elderly group of patients in THE-group, with associated co-morbidities, but also subjective reasons, as the surgeries were performed by a group of general surgeons with variable experience in thoracic procedures, for whom the transhiatal approach was more convenient. Above all, the final argument was based on the clinico-therapeutic particularities of esophageal carcinoma in our geographical area, which finally warrant the transhiatal approach as an acceptable procedure, i.e. late diagnosis, generally in advanced stages of the disease, consecutively with low rate of curative resections, all of these thereby influencing the prognosis and survival rates (3).

The post-esophagectomy mortality and morbidity rates have dropped consistently in the past years. A recent report published by the Health and Social Care Information Centre (HSCIC) noted 30-day mortality rates of $1.7 \%$ with a rather constant global morbidity rate of approximately 30\%, more than half of which $(16.2 \%)$ were represented by respiratory complications (22). Despite being comparable with reports from surgical centers with similar surgical volume (23), our postoperative mortality and morbidity rates are rather distant from those mentioned above.

For a better standardization of our own results, we described the postoperative surgical complications in accordance with the Clavien Dindo classification system (24). This system uses a gradual ranking ranging from simple complications which do not require re-interventions (Grade I and II), to cases which require additional surgery, are life threatening, or induce mortality (Grade III, IV, and V, respectively).

Anastomotic failure is still considered to be the major drawback of the transhiatal approach, with a reported rate as high as $25 \%$ in the literature (25). We have had an important number of respiratory complications and anastomosis fistula; regarding these fistulas, the majority were conservatively managed and did not significantly contribute to the in-hospital mortality, even though they were recently followed by an important number of cervical anastomosis stenosis. Among surgicalrelated complications, we also noted two cases of conduit necrosis, which were both followed by mediastinitis, severe sepsis and death. Our $9.09 \%$ mortality is high, but could be explained by the fact that half of the deaths had non-surgicalrelated causes (one embolism, two IMA). In this perspective, we might state that our procedure-related mortality rate is consistent with that reported by HV centers, as mentioned by Birkmeier et al. (5).

In the last decades, the survival rates following esophagectomy have significantly improved, mostly due to a decrease in the postoperative mortality and associated multimodal therapy $(26,27)$. Several studies, including a recent meta-analysis, demonstrated better long-term survival after esophagectomies performed either in HV centers or by high-volume surgeons (2830). Even if there are few situations in which LV hospital could achieve similar results with their HV counterparts, these results are strongly influenced by some system characteristics, individual surgeon volume or patient co-morbidities $(31,32)$. Our survival rates are different from those reported in centers with similar esophageal resection volume, but the results could not be judged only in the view of a low volume center as they are described in the literature. The study population included patients operated on in advanced stages of the disease, with inconsistent preoperative and postoperative oncologic treatment. Among the factors which clearly influenced survival rates, we noted T- and $\mathrm{N}$-category and the complicated postoperative course.

This study has some important drawbacks such as the limited number of patients included and the relatively long period of analysis, during which the preoperative work-up protocol suffered major modifications. However, we might conclude that morbidity and in-hospital mortality after THE performed in low-volume centers, despite being significantly higher than reported in HV centers or different work groups, could be kept in reasonable rates. With regards to survival rates, at least in our geographical region, these are consistently influenced, besides the surgical volume, by the advanced stage of the disease at the moment of diagnosis, inconsistency in preoperative and postoperative oncological treatment. 
Moreover, by being the first retrospective analysis of esophagectomy results from a surgical volume perspective performed in Romania to the best of our knowledge, our study draws further attention to several health system deficiencies. In this respect, we call for the standardization of therapeutic and diagnostic protocols for esophageal cancer and the centralization of these major oncologic interventions in surgical excellence centers. These measures can increase the surgical volume and thus contribute to the reduction of mortality and morbidity and the improvement of survival rates. Altogether, such measures have the potential to raise the standard of care for patients diagnosed with esophageal cancer in Romania.

Ethics Committee Approval: Ethics committee approval was received for this study from the ethics committee of the hospitals.

Informed Consent: Written informed consent was obtained from patients who participated in this study.

Peer-review: Externally peer-reviewed.

Author contributions: Concept - R.M.N.; Design - R.M.N.; Supervision - B.S., G.H.; Resource - B.S., S.M., V.S.; Materials R.M.N., B.S.; Data Collection\&/or Processing - R.M.N., D.T.S., B.S., V.S., S.M.; Analysis\&/or Interpretation - R.M.N., D.T.S., B.S.,S.M.,V.S.,G.H.; Literature Search - D.T.S., R.M.N.,S.M.; Writing R.M.N.; Critical Reviews - R.M.N.,V.S., S.M., D.T.S., B.S.,G.H.

Conflict of Interest: No conflict of interest was declared by the authors.

Financial Disclosure: The authors declared that this study has received no financial support.

\section{REFERENCES}

1. Almhanna K, Shridhar R, Meredith KL. Neoadjuvant or adjuvant therapy for resectable esophageal cancer: is there a standard of care? Cancer Control 2013;20:89-96.

2. Kawoosa NU, Dar AM, Shama ML, Ahangar AG, Lone GN, Bhat MA, et al. Transthoracic versus transhiatal esophagectomy for Esophageal carcinoma: Experience from a single tertiary care institution. World J Surg 2011;35:1296-302. [CrossRef]

3. Neagoe RM, Sala D, Voidazan S, Bancu S, Kiss L, Suciu H. Transthoracic versus Transhiatal esophagectomy: a permanent dilemma. Our 15-year experience. Chirurgia (Buc) 2013;108:780-87.

4. Barreto JC, Posner MC. Transhiatal versus transthoracic esophagectomy for esophageal cancer. World $J$ Gastroenterol 2010;16:3804-10. [CrossRef]

5. Birkmeyer JD, Siewers AE, Finlayson EV, Stukel TA, Lucas FL, Batista I, et al. Hospital volume and surgical mortality in the United States. N Engl J Med 2002;346:1128-37. [CrossRef]
6. Begg CB, Cramer LD, Hoskins WJ, Brennan MF. Impact of hospital volume on operative mortality for major cancer surgery. JAMA 1998;280:1747-51. [CrossRef]

7. Orringer MB, Sloan H. Esophagectomy without thoracotomy. $J$ Thorac Cardiovasc Surg 1978;76:643-54.

8. Müller JM, Erasmi H, Stelzner M, Zieren U, Pichlmaier H. Surgical therapy of oesophageal carcinoma. Br J Surg 1990;77:845-57. [CrossRef]

9. Orringer MB, Marshal B, Chang AC, Lee J, Pickens A, Lau CL. Two thousand transhiatal esophagectomies: changing trends, lessons learned. Ann Surg 2007;246:363-72. [CrossRef]

10. Constantinoiu S. Subtotal abdomino-cervical esophagectomy (transhiatal, without thoracotomy, or Orringer's technique). Chirurgia (Bucur) 2005;100:479-87.

11. Halm EA, Lee $C$, Chassin MR. Is volume related to outcome in health care? A systematic review and methodologic critique of the literature. Ann Intern Med 2002;137:511-20. [CrossRef]

12. Dimick JB, Goodney PP, Orringer MB, Birkmeyer JD. Specialty training and mortality after esophageal cancer resection. Ann Thorac Surg 2005;80:282-86. [CrossRef]

13. Valean S, Armean P, Resteman S, Nagy G, Muresan A, Mircea PA. Cancer mortality in Romania,1995-2004. Digestive sites: esophagus, stomach, colon and rectum, pancreas, liver, gallbladder and billiary tree. J Gastrointestin Liver Dis 2008;17:9-14.

14. Gaillard J, Bouchayer M, Haguenauer JP. Le risqué de degenerescence cancereuse tardive dans les stenosescaustique de l'oesophage. Ann Otol Rhyno Laryng 1970;87:634-44.

15. Ti TK. Oesophageal carcinoma associated with corrosive injury- prevention and treatment by esophageal resection. Br J Surg 1983;70:223-25. [CrossRef]

16. Zamfir D, Bancu: Urgenţe medico-chirurgicale în patologia esofagului, ed. Veritas, Tg. Mureş, 2000.

17. Howard JM, Ryan L, Lim KT, Reynolds JV. Oesophagectomy in the management of end-stage achalasia - case reports and a review of the literature. Int J Surg 2011;9:204-8. [CrossRef]

18. Molena D,Yang SC. Surgical management of end-stage achalasia. Semin Thorac Cardiovasc Surg 2012;24:19-26. [CrossRef]

19. Neagoe R, Zamfir D, Toma L, Esianu M, Popescu G, Daniela Sala. Revascularizarea grefonului colic-o soluţie de îmbunătăţire a viabilităţii substitutului esofagian. Jurnalul de Chirurgie (Iaşi) 2007;3:360-63.

20. Kesler KA, Pillai ST, Birdas TJ, Rieger KM, Okereke IC, Ceppa D, et al. Supercharged isoperistaltic colon interposition for long-segment esophageal reconstruction. Ann Thorac Surg 2013;95:1162-69. [CrossRef]

21. Davies AR, Forshaw MJ, Khan AA, Noorani AS, Patel VM, Strauss DC, et al. Transhiatal esophagectomy in a high volume institution. World J Surg Oncol 2008;6:88. [CrossRef]

22. HSCIC. 2013. National Oesophago-Gastric Cancer Audit 2013 [online]. Available from: http://www.hscic.gov.uk/catalogue/ PUB11093/clin-audi-supp-prog-oeso-gast-2013-rep.pdf

23. Wouters MW, Wijnhoven BP, Karim-Kos HE, Blaawgeers HG, Stassen LP, Steup WH, et al. High-volume versus low-volume for esophageal resections for cancer: the essential role of case-mix adjustments based on clinical data. Ann Surg Oncol 2008;15:80-7. [CrossRef] 
24. Dindo D, Demartines N, Clavien PA. Classification of surgical complications: a new proposal with evaluation in a cohort of 6336 patients and results of a survey. Ann Surg 2004;240:205-13. [CrossRef]

25. Hsu HH, Chen JS, Huang PM, Lee JM, Lee YC. Comparison of manual and mechanical cervical esophagogastric anastomosis after esophageal resection for squamous cell carcinoma: a prospective randomized controlled trial. Eur J Cardiothorac Surg 2004;25:1097-101. [CrossRef]

26. Chang AC, Ji H, Birkmeyer NJ, Orringer MB, Birkmeyer JD. Outcomes after transhiatal and transthoracic esophagectomy for cancer. Ann Thorac Surg 2008;85:424-9. [CrossRef]

27. Gebski V, Burmeister B, Smithers BM, Foo K, Zalcberg J, Simes J; Australian Gastro-intestinal Trials Group: Survival benefirs from neoadjuvant chemotherapy or chemotherapy in oesophageal carcinoma: a meta-analysis. Lancet Oncol 2007;8:226-34. [CrossRef]

28. Donohoe CL, O'Farrell NJ, Ravi N, Reynolds JV. Evidencebased selective application of transhiatal esophagectomy in a high-volume esophageal center. World J Surg 2012;36:98103. [CrossRef]

29. Feo CV, Villaflor VM, Patti MG. Should esophageal resections for cancer be performed in high-volume centers only? Updates Surg 2011;63:147-50. [CrossRef]

30. Wouters MW, Gooiker GA, van Sandick JW, Tollenaar RA. The volume-outcome relation in the surgical treatment of esophageal cancer: a systematic review and meta-analysis. Cancer 2012;118:1754-63. [CrossRef]

31. Funk LM, Gawande AA, Semel ME, Lipsitz SR, Berry WR, Zinner MJ, et al. Esophagectomy outcomes at low-volume hospitals: the association between systems characteristics and mortality. Ann Surg 2011;253:912-7. [CrossRef]

32. Courrech Staal EF, van Coevorden F, Cats A, Aleman BM, van Velthuysen ML, Boot H, et al. Outcome of low-volume surgery for esophageal cancer in a high-volume referral center. Ann Surg Oncol 2009;16:3219-26. [CrossRef] 